\title{
The Use of Cost-Benefit Analysis in Environmental Policy ${ }^{1}$
}

\author{
Elizabeth F. Pienaar ${ }^{2}$
}

From the economists' point of view the environment provides various goods and services such as:

- Raw materials (e.g., water, soil, timber, minerals) that are transformed into consumer products

- Energy (e.g., oil, coal, gas) that fuels manufacturing, industrial processes, heating and cooling of buildings, transport, etc.

- Air, water, food, and shelter that support human life

- Genetic resources

- Recreational opportunities from outdoor activities

However, the use of these goods and services may cause environmental degradation. For example, water pollution from industrial processes and agriculture negatively affects fisheries and recreational opportunities, and results in the loss of wildlife and habitat. The use of fossil fuels for transport, production processes, and heating and cooling generates air pollution and acid rain. Deforestation results in soil erosion, the loss of wildlife habitat, and degradation of watersheds. The introduction of exotic plant and animal species results in habitat degradation and loss of native species.

\section{Benefits and Costs}

When analyzing environmental problems, economists consider both the benefits (B) and costs (C) of actions. If benefits exceed costs $(B>C)$ then economic theory supports that action. For example, if the total benefits of conserving land (e.g. through the generation of ecosystem services, the provision of tourism opportunities, and the protection of wildlife habitat) exceed the costs (e.g. the costs of protecting and managing the land, and the costs of forgoing economic activity and income from urban development, industry, or agricultural production) then cost-benefit analysis would support conservation of the land. However, great care must be taken to accurately identify and quantify benefits and costs to determine whether an action is cost-benefit justified. Stakeholders may have an incentive to overstate costs or benefits, in order to influence decision-making.

Total benefits are derived from the demand curve. The demand curve maps the relationship between the quantity of a good consumed and the value that an individual (or society) places on each unit of consumption. The demand curve is a graphical representation of the maximum amount of money an individual or society is willing to pay for each additional unit of a good. The area under the demand curve measures total willingness to pay for the good. Total willingness to pay (WTP) is equivalent to the total benefits derived from consumption of a good. In Figure 1, the shaded area represents total benefits derived from consumption of $\mathrm{Q}$ units of a good.

1. This document is WEC338, one of a series of the Wildlife Ecology and Conservation Department, UF/IFAS Extension. Original publication date September 2013. Visit the EDIS website at http://edis.ifas.ufl.edu.

2. Elizabeth F. Pienaar, assistant professor, Department of Wildlife Ecology and Conservation; UF/IFAS Extension, Gainesville, FL 32611.

The Institute of Food and Agricultural Sciences (IFAS) is an Equal Opportunity Institution authorized to provide research, educational information and other services only to individuals and institutions that function with non-discrimination with respect to race, creed, color, religion, age, disability, sex, sexual orientation, marital status, national origin, political opinions or affiliations. For more information on obtaining other UF/IFAS Extension publications, contact your county's UF/IFAS Extension office. 


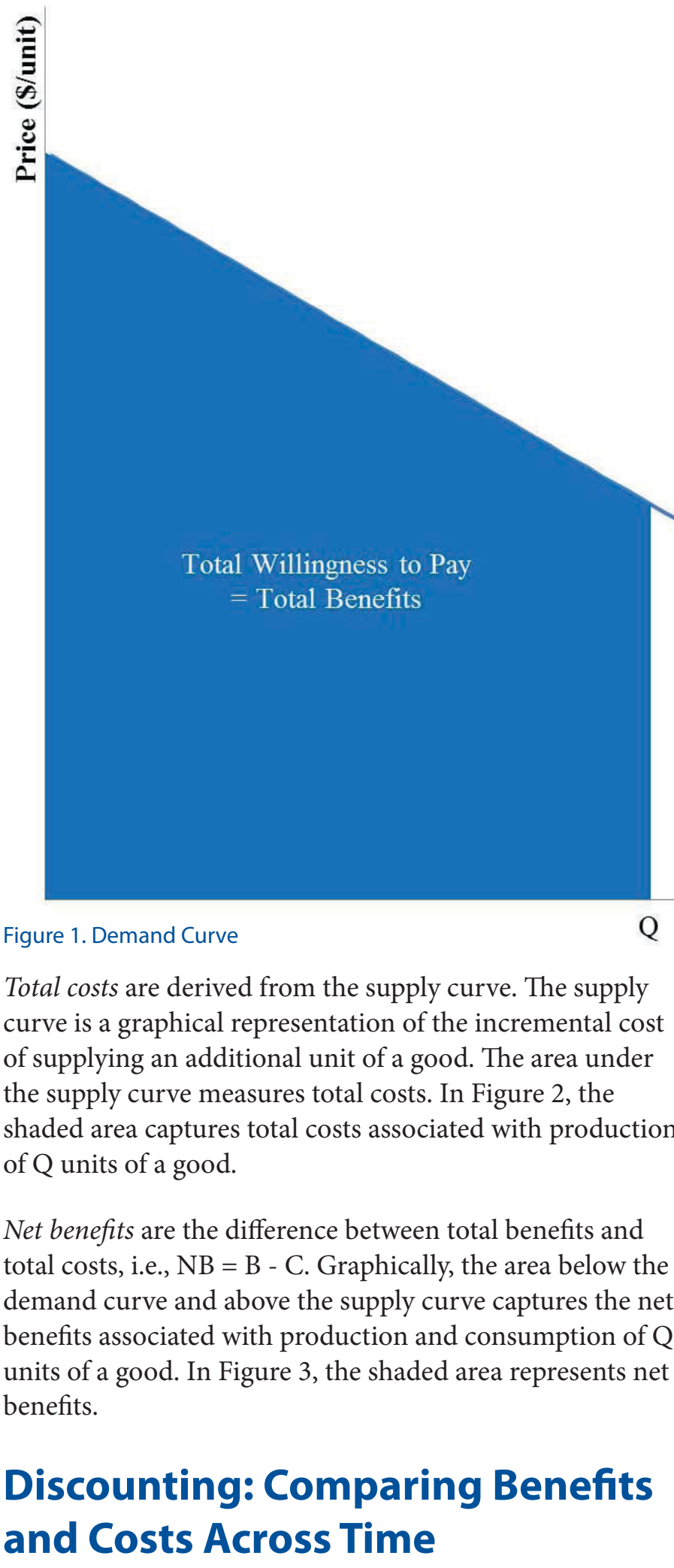

The above graphical representation demonstrates how the size of net benefits at a single point in time is calculated. However, time is typically an important factor in considering whether to protect or utilize environmental goods. Both the magnitude and timing of benefits and costs should be
—Demand (Marginal Benefit) Curve

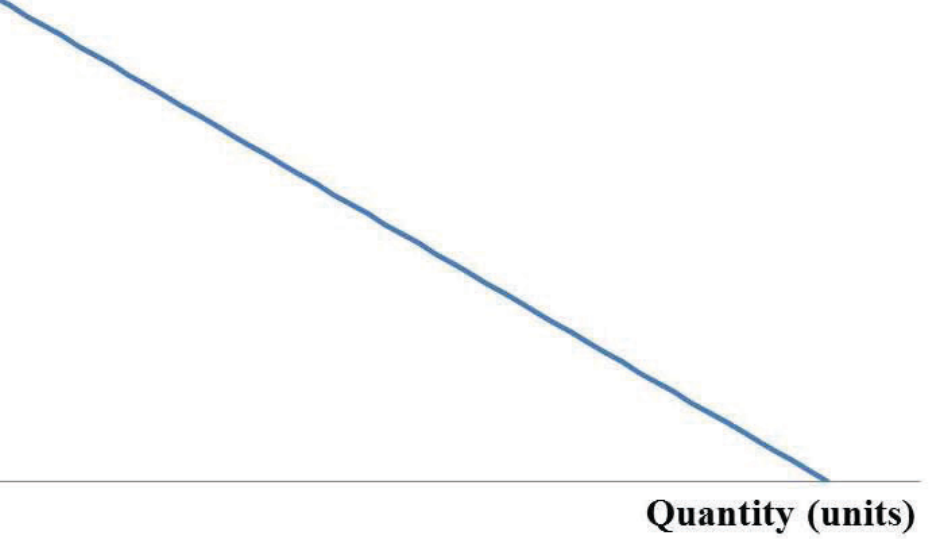

incorporated in economic analyses of environmental issues, i.e., the present value of net benefits should be calculated.

Present value calculations incorporate the value of money over time. For example, $\$ 1$ invested at a $7 \%$ rate of interest is worth $\$ 1.07$ in one year. This implies that $\$ 1.07$ received one year from now is equivalent to $\$ 1$ today. If $r$ is the discount rate (i.e., the interest rate used to value money over time), then the present value (PV) of a stream of net benefits $\left\{\mathrm{NB}_{0}, \ldots, \mathrm{NB}_{\mathrm{n}}\right\}$ received over a period of $n$ years is:

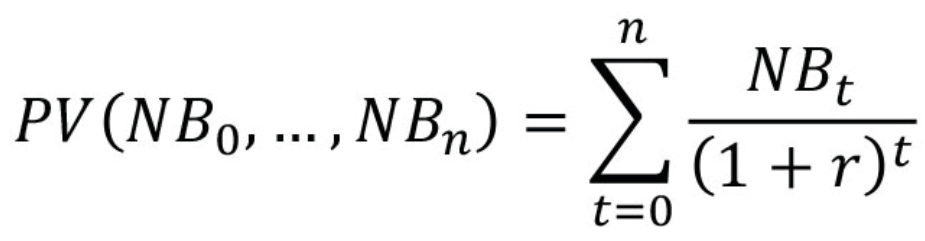

where $\mathrm{NB}_{0}$ are net benefits in the current period. The process of calculating the present value of net benefits is called discounting.

The higher the discount rate applied, the greater the emphasis placed on current benefits and/or costs relative to future 
benefits and/or costs. Both agencies and interest groups may manipulate present value calculations by increasing or decreasing the discount rate. For example, assume that an environmental intervention will cost $\$ 20,000$ today but it will generate $\$ 50,000$ in benefits 10 years from now. If a discount rate of $5 \%$ is used then the present value of the intervention is $\$ 10,696$ and the intervention is cost-benefit justified. If a discount rate of $7 \%$ is used then the present value of the intervention is still positive $(\$ 5,417)$ but it is smaller. The intervention is still cost-benefit justified. But if a $10 \%$ discount rate is used then the present value of the environmental intervention is $-\$ 723$, and the intervention is no longer cost-benefit justified. Economic studies should state which discount rates are applied, why these discount rates were chosen, and how changing the discount rate alters the results. The Office of Management and Budget, the section of the Executive Office of the President of the United States that is responsible for assessing the economic impacts of all Federal regulations, recommends the use of a real discount rate of $7 \%$.

\section{Efficiency: Finding the Optimal Outcome}

Efficiency is the criterion used for choosing between different environmental alternatives, e.g., different rates of harvest of a fish stock. Static efficiency is achieved when net benefits for a single period of time (typically one year) are maximized. Dynamic efficiency is achieved when the present value of net benefits over a period of years is maximized. Dynamic efficiency takes the timing of benefits and costs into account.

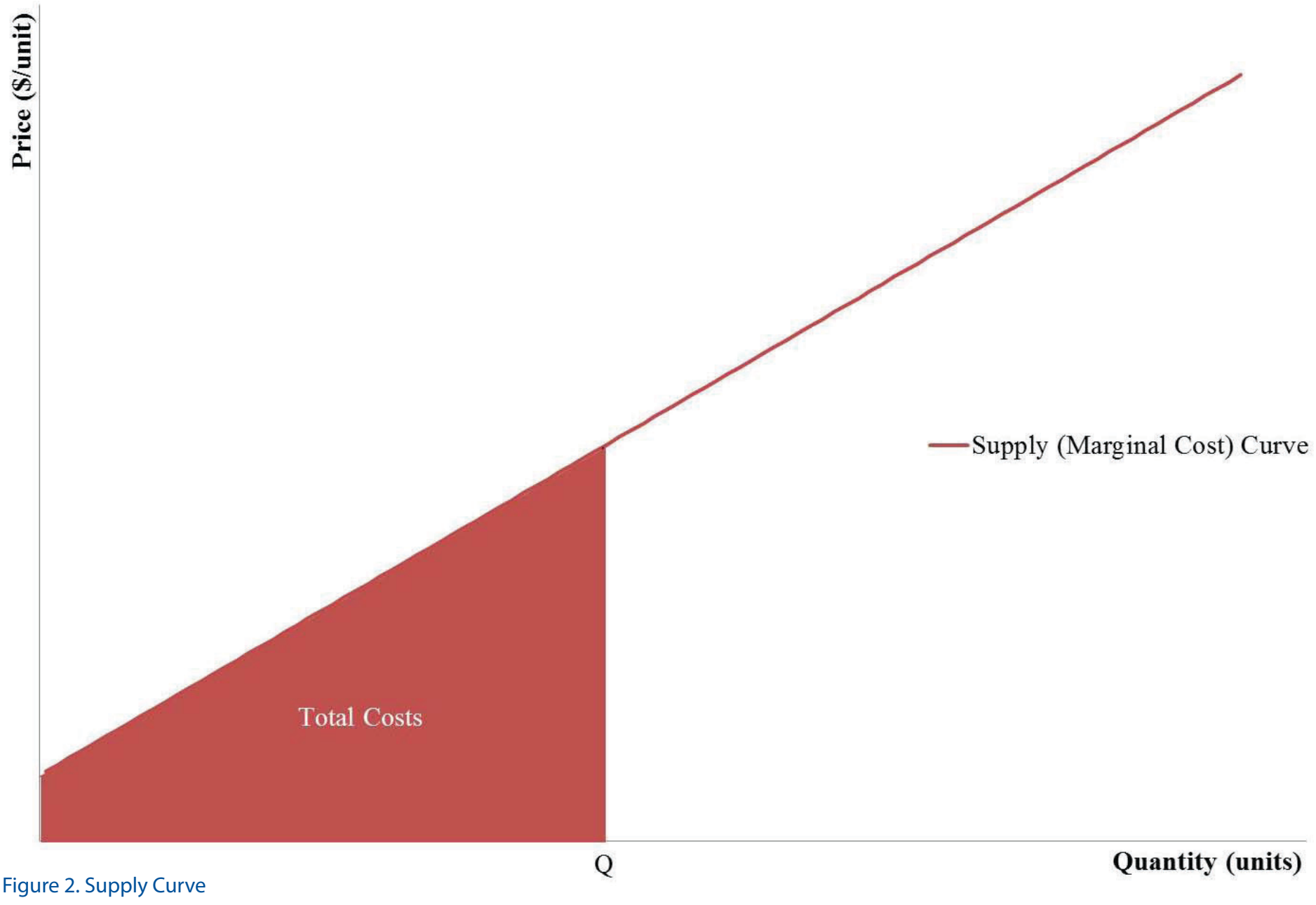




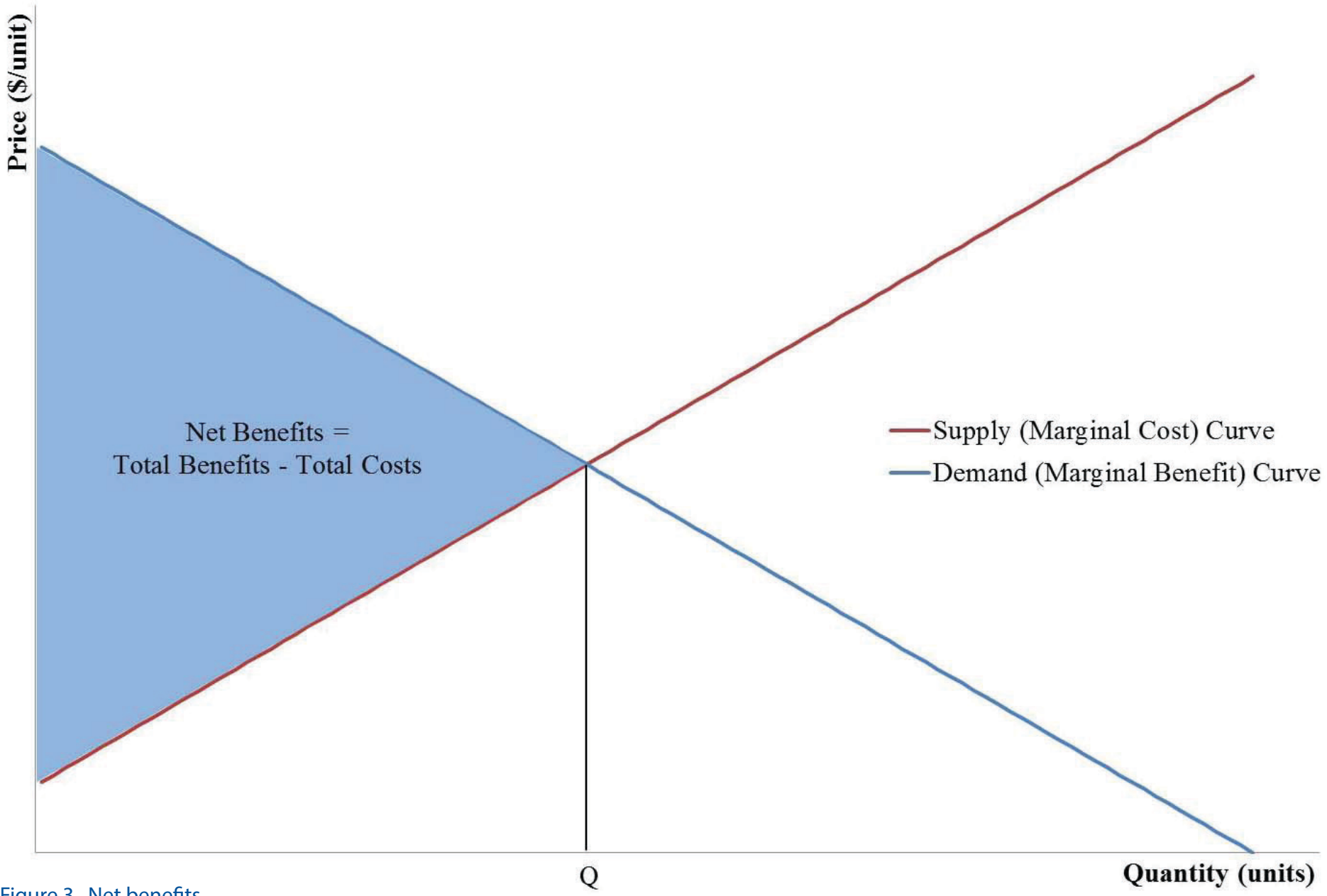

Figure 3. Net benefits

\section{Use of Cost-Benefit Analysis}

Given budget constraints and competition for financial resources, cost-benefit analysis may be used to persuade legislators, the general public, business groups, landowners, conservation and natural resource agencies, and other relevant stakeholders to support or fund conservation programs. In fact, the Office of Information and Regulatory Affairs (OIRA) within the Office of Management and Budget uses cost-benefit analysis to review Federal regulations, including environmental regulations.

By contrast, the state of Florida requires a cost-effectiveness analysis of rules and regulations under Fla. Rev. Stat. $\$$ 120.541. A cost-effective rule is one that minimizes the costs of achieving a given policy objective or outcome (e.g., maintaining the population of a species at or above a critical level). This is a less stringent requirement than demonstrating that a rule is cost-benefit justified because only costs are measured and minimized; benefits are not quantified and compared to costs. Nonetheless, demonstrating that the benefits of a program exceed the costs provides additional justification for funding and implementing policies or programs.

\section{Example: Clean Air Act}

In a 1997 report to Congress, the EPA provided a cost-benefit analysis of the Clean Air Act (Table 1). Using a discount rate of 5\%, the EPA estimated that the Clean Air Act had generated $\$ 21.7$ trillion in net benefits between 1970 and 1990 (Tietenberg and Lewis 2009). Accordingly, the Clean Air Act was cost-benefit justified, although the results do not prove that the Act was efficient. To show dynamic efficiency, it would have been necessary to demonstrate that the present value of net benefits was maximized.

Table 1. Monetized Benefits and Costs of the U.S. Clean Air Act, 1970-1990 (billions of 1990 dollars)

\begin{tabular}{|l|l|l|l|l|l|}
\hline & $\mathbf{1 9 7 5}$ & $\mathbf{1 9 8 0}$ & $\mathbf{1 9 8 5}$ & $\mathbf{1 9 9 0}$ & \multicolumn{1}{|c|}{$\begin{array}{c}\text { Present } \\
\text { Value }\end{array}$} \\
\hline Benefits $^{\mathrm{a}}$ & 355 & 930 & 1,155 & 1,248 & 22,200 \\
\hline Costs $^{\mathrm{b}}$ & 14 & 21 & 25 & 26 & 523 \\
\hline Net Benefits & 341 & 909 & 1,130 & 1,220 & 21,700 \\
\hline
\end{tabular}

aThese are the mean (average) benefits. Due to the uncertainties involved, EPA also calculated low and high estimates.

${ }^{\mathrm{b}}$ These are the annualized costs. (Many investments in pollution control involve the purchase of durable equipment that lasts many years.) Rather than put all of the expense in the year of purchase, EPA distributed the costs over the useful lives of this equipment. Source: Tietenberg and Lewis 2009 
Estimated benefits included: reduced death rates and lower incidences of chronic bronchitis, lead poisoning, strokes, respiratory diseases, and heart disease; improved visibility; reduced structural damages; and increased agricultural productivity. EPA was unable to quantify multiple potential ecosystem effects of the Clean Air Act. As such, the benefits of the Clean Air Act were likely underestimated.

Estimated costs included: higher costs of goods and services owing to costs of installing, operating, and maintaining pollution control equipment, resulting in higher prices for goods and services; and the costs of designing and implementing the Clean Air Act regulations, e.g., monitoring costs and costs of enforcing compliance with the regulations.

A further study by the EPA showed that between 1990 and 2020 the Clean Air Act is expected to generate $\$ 65$ billion in costs (measured in 2006 dollars) and \$1,951 billion in benefits. Estimated net benefits of the Clean Air Act between 1990 and 2020 are $\$ 1,886$ billion (US EPA 2011).

\section{Example: Feral Swine Control in Savannas Preserve State Park, Florida}

Feral swine are responsible for considerable habitat degradation. Estimates for the year 2003 show that feral swine damaged 19\% of the exposed marsh in Savannas Preserve State Park in Florida (Engeman et al. 2004). The Savannas Preserve State Park protects the largest and most intact remnant of Florida's east coast savannas.

The benefits of swine control can be calculated by estimating the value of reduced habitat damage by feral swine. Based on prices obtained from wetland mitigation banking (see http://www.ecy.wa.gov/programs/sea/wetlands/mitigation/banking/ for an explanation of wetland banking), the value of freshwater emergent habitat (also referred to as marshes or sloughs) is $\$ 247,742 /$ hectare. In 2003 , total estimated damage by feral swine to freshwater emergent habitat was $\$ 1,238,760$ (i.e. $\$ 247,742 /$ hectare $\times 5$ hectares of damaged habitat). Over a year the US Department of Agriculture's Wildlife Services (USDA/WS) undertook feral swine control efforts. As a result of these control efforts, in 2004, the total number of hectares of freshwater emergent habitat damaged by feral swine fell to 0.95 hectares. Accordingly, total costs of feral swine damage to freshwater emergent habitat fell to $\$ 235,355$ (i.e. $\$ 247,742 /$ hectare $\times$ 0.95 hectares of damaged habitat). Swine control resulted in approximately $\$ 1,003,355$ in benefits, or reduced habitat damage by feral swine (see Table 2). This estimated value of swine control in Table 2 does not include the value of rare or at risk species. Accordingly, the calculated benefits may underestimate the true benefits of feral swine control (Engeman et al. 2004).

Table 2. Benefits of Swine Control

\begin{tabular}{|l|l|l|r|}
\hline \multicolumn{1}{|c|}{ Year } & $\begin{array}{c}\text { Freshwater } \\
\text { Emergent } \\
\text { Habitat } \\
\text { Damaged by } \\
\text { Feral Swine }\end{array}$ & $\begin{array}{c}\text { Value of } \\
\text { Freshwater } \\
\text { Emergent } \\
\text { Habitat }\end{array}$ & $\begin{array}{c}\text { Total Costs of } \\
\text { Feral Swine } \\
\text { Damage }\end{array}$ \\
\hline 2003 & 5 hectares & $\begin{array}{l}\$ 247,742 / \\
\text { hectare }\end{array}$ & $\$ 1,238,760$ \\
\hline 2004 & 0.95 hectares & $\begin{array}{l}\$ 247,742 / \\
\text { hectare }\end{array}$ & $\$ 235,355$ \\
\hline Difference & 4.05 hectares & & $\$ 1,003,355$ \\
\hline
\end{tabular}

The total cost of trapping and removing feral swine in 2003 was $\$ 7,500$. In total, 64 swine were removed during control efforts, i.e. the cost per swine removed was $\$ 117$. The net benefits of the program were $\$ 995,855$ ( $\$ 1,003,355$ - $\$ 7,500)$ (Engeman et al. 2004). Swine control in the Savannas Preserve State Park was cost-benefit justified, even if the benefits of swine control are underestimated.

\section{Further Reading}

Engeman, R. M., H. T. Smith, R. Severson, M. A. Severson, J. Woolard, S. A. Shwiff, B. Constantin, and D. Griffin. 2004. "Damage reduction estimates and benefit-cost ratios for feral swine control from the last remnant of a basin marsh system in Florida." Environmental Conservation, 31, 207-211.

Office of Management and Budget. 1992. Guidelines and Discount Rates for Benefit-Cost Analysis of Federal Programs, Circular No. A-94 Revised, available at: http://www.whitehouse.gov/omb/circulars_a094\#8

Tietenberg, T., and L. Lewis. 2009. Environmental and Natural Resource Economics, $8^{\text {th }}$ Edition. Boston: Pearson Education, Inc.

U.S. Environmental Protection Agency. 2011. The Benefits and Costs of the Clean Air Act from 1990 to 2020: Summary Report. 34 pp., available at: http://www.epa.gov/cleanairactbenefits/feb11/summaryreport.pdf 